Article

\title{
The Influence of Cellulose Nanocrystals on the Hydration and Flexural Strength of Portland Cement Pastes
}

\author{
Tengfei Fu ${ }^{1}{ }^{*}$, Francisco Montes ${ }^{2}$, Prannoy Suraneni ${ }^{3}$, Jeffrey Youngblood ${ }^{2}$ and Jason Weiss ${ }^{1}$ \\ 1 School of Civil and Construction Engineering, Oregon State University, Corvallis, OR 97331, USA; \\ jason.weiss@oregonstate.edu \\ 2 School of Materials Engineering, Purdue University, West Lafayette, IN 47907, USA; \\ fmontemo@purdue.edu (F.M.); jpyoungb@purdue.edu (J.Y.) \\ 3 Department of Civil, Architectural and Environmental Engineering, University of Miami, Coral Gable, \\ FL 33146, USA; suranenip@miami.edu \\ * Corresponding author: felixftf@gmail.com; Tel.: +1-541-737-3052
}

Received: 31 July 2017; Accepted: 4 September 2017; Published: 7 September 2017

\begin{abstract}
Recent research has shown that cellulose nanocrystals (CNCs) can be used at low dosage levels (approximately $0.2 \%$ by volume of cement) to increase the extent of hydration and to improve the flexural strength of cement pastes. However, the previous work was based on using a CNC made from a single source material and processing technique and was performed using only Type $\mathrm{V}$ cement. This work examines the influence of various raw material sources and processing techniques used to make the CNCs. In total, nine different CNCs were investigated with pastes made using Type I/II and Type V cements. Isothermal calorimetry (IC), thermogravimetric analysis (TGA) and ball-on-three-ball (B3B) flexural strength testing were used to quantify the performance of CNC-cement composites. IC and TGA results showed that CNCs increased the degree of hydration in all systems. IC results showed that the increase in total heat release was greater in the Type V than in the Type I/II cement paste systems. B3B flexural testing indicated an increase in flexural strength of up to $20 \%$ with both Type I/II and Type V systems. These results also showed that the performance of CNC-cement composites can be affected by the source and manufacturing process used to make the CNC.
\end{abstract}

Keywords: cellulose; nanomaterials; cellulose nanocrystals; Portland cement; flexural strength; cement hydration

\section{Introduction}

The use of nanotechnology and nanomaterials has been proposed to develop advanced cement composites with improved performance, durability and sustainability [1,2]. Cellulose nanomaterials $(\mathrm{CN})$, derived from cellulose fibers obtained from wood and plants, are intrinsically sustainable and possess a unique combination of properties, such as high tensile strength, high elastic modulus, low thermal expansion and relatively low density compared with other reinforcing materials [3]. CNs have been successfully used in many applications such as additives (to adhesives, paper-based products, drilling fluids, cement-based materials), food coatings, transparent-flexible electronics, catalysis support structures and many biomedical applications $[3,4]$.

In recent years, cellulose nanocrystals (CNCs) have been drawing increasing attention as a potential additive and nano-reinforcing materials in cementitious materials. A recent review of the research on $\mathrm{CN}$-cement composites was developed [5] and for brevity will not be repeated here. Another review of the preparation, properties and applications of cellulose bio nanocomposites can be found in the literature [6]. CNCs from wood or plant materials typically have a spindle-like particle 
morphology with a width of 3-20 nm and a length of 50-500 nm [7]. These CNCs are nearly $100 \%$ cellulose, with high crystallinity. CNCs have unique properties such as high aspect ratio, high elastic modulus, high tensile strength, low density and surfaces that allow easy water-dispersibility and can be further functionalized [7]. As an additive to cementitious materials, CNCs have been shown to improve mechanical properties [8,9], increase the degree of hydration [9], and enhance the microstructure $[10,11]$ of cementitious materials. Previous work showed that CNCs, even at low dosages $(0.2 \%$ by volume of cement), significantly increased the flexural strength (approximately 20-30\%) of cement pastes [9]. It should be noted that due to the significantly smaller size of CNCs compared to conventional cellulose materials, the strength enhancing mechanism for CNC-cement composites is likely different from the fiber bridging mechanism [12], which applies to many other fiber-reinforced cement composites. The majority of CNCs ( $>95 \%$ ) are small enough that they are believed to be adsorbed on the surface of the cement particles providing: (1) a steric stabilization effect similar to polycarboxylate type water reducers and (2) the creation of paths for water molecules to more easily diffuse through the hydrated shell and reach the inner unhydrated core, which was referred to as a short circuit diffusion (SCD) effect in previous research [8,9]. Nanoindentation studies revealed that higher stiffness C-S-H exists in CNC-rich regions in hydrated cement pastes [10]. Flores et al. [11] reported a small increase in the volume fraction of high density $\mathrm{C}-\mathrm{S}-\mathrm{H}$ and a decrease in the volume fraction of low-density $\mathrm{C}-\mathrm{S}-\mathrm{H}$ in CNC-cement composites. In the same study, Fourier transform infrared spectroscopy (FTIR) results indicated that there are possible bonds formed between CNCs and hydration products [11].

In spite of the above-mentioned research, there is still a scarcity of work on the use of CNCs in cementitious materials. Previous research has mostly focused on a single CNC source with a single cement type. As more and more commercially-viable CNCs emerge, it is important to better understand cement-CNC interactions. This research aims to investigate the effect of different CNC sources on different cement types. There are essential questions to ask:

- Will CNCs from different raw material sources and from different processing procedures perform differently?

- Will CNCs perform equally well in cements of different types and chemical compositions?

- What are the most appropriate screening tests to evaluate the performance of CNC-cement composites?

- What are the factors that influence the performance of CNC-cement composites?

In an attempt to answer these questions, CNCs from nine different sources/processing techniques were investigated in cementitious composites made using Type I/II and Type V cement. The influence of CNCs on the hydration and mechanical properties of cement paste were studied using isothermal calorimetry (IC), thermogravimetric analysis (TGA) and ball-on-three-ball (B3B) flexural strength testing.

\section{Experimental Methods}

\subsection{Materials}

The composition of the cements used is shown in Table 1. The Type I/II cement is selected as these cements generally have the widest application, while the Type V cement is selected for this research due to its low aluminate content and use in high performance thin reinforced cement-based products [13]. 
Table 1. Cement Chemical composition.

\begin{tabular}{|c|c|c|}
\hline \multirow{2}{*}{ Components } & \multicolumn{2}{|c|}{ Mass (\%) } \\
\hline & Type I/II & Type V \\
\hline Silicon dioxide $\left(\mathrm{SiO}_{2}\right)$ & 20.1 & 21.9 \\
\hline Aluminum oxide $\left(\mathrm{Al}_{2} \mathrm{O}_{3}\right)$ & 4.7 & 2.8 \\
\hline Ferric oxide $\left(\mathrm{Fe}_{2} \mathrm{O}_{3}\right)$ & 3.5 & 4.5 \\
\hline Calcium oxide $(\mathrm{CaO})$ & 63.7 & 64.3 \\
\hline Magnesium oxide $(\mathrm{MgO})$ & 0.7 & 2.4 \\
\hline Sulfur trioxide $\left(\mathrm{SO}_{3}\right)$ & 3.1 & 2.9 \\
\hline Loss on ignition & 2.6 & 0.85 \\
\hline Limestone & 4.0 & 0.51 \\
\hline Insoluble residue & 0.3 & 0.15 \\
\hline Equivalent alkali as $\mathrm{Na}_{2} \mathrm{O}$ & 0.51 & 0.19 \\
\hline $\mathrm{C}_{3} \mathrm{~S}^{*}$ & 53 & 64 \\
\hline $\mathrm{C}_{2} \mathrm{~S} *$ & 18 & 13 \\
\hline $\mathrm{C}_{3} \mathrm{~A} *$ & 7 & 0 \\
\hline $\mathrm{C}_{4} \mathrm{AF}^{*}$ & 11 & 13 \\
\hline Blaine fineness $\left(\mathrm{m}^{2} / \mathrm{kg}\right)$ & 364 & 305 \\
\hline
\end{tabular}

There were in total nine CNCs used in this research, and their characteristics are listed in Table 2. All CNCs were provided as aqueous suspensions with different solid contents, except for CNC6 and $\mathrm{CNC7}$, which were in the form of dry powder. CNC1, CNC2 and CNC3 were provided by the USDA Forest Service-Forest Products Laboratory, Madison, WI, USA [14]. They were produced from wood pulp (CNC1), cotton (CNC2) and Cladophora (algae species, CNC3), using sulfuric acid (Columbus Chemical Industries, Columbus, WI, USA) (64\% by weight) hydrolysis for $60 \mathrm{~min}$ at $45{ }^{\circ} \mathrm{C}$ in an oxygen-free atmosphere. Following hydrolysis, the CNCs were diluted with reverse osmosis water, and then, sodium chloride was added to remove the color. Finally, the acid was neutralized by the addition of sodium hydroxide. The final product was in the form of aqueous suspension. CNC4-CNC9 were from pilot plants. $\mathrm{CNC} 4$ and $\mathrm{CNC} 5$ were from the same source, and both were made from acetate dissolving pulp (Western Hemlock). Their isolation method was oxidative in nature and did not involve acid hydrolysis; thus, no sulfate esters are grafted on the surface of these CNCs. The only difference between $\mathrm{CNC} 4$ and $\mathrm{CNC} 5$ is the oxidative process: $\mathrm{CNC} 4$ underwent a transition metal catalyzed oxidation process while $\mathrm{CNC} 5$ underwent a natural oxidative process. $\mathrm{CNC} 6$ was produced on a pilot scale from softwood dissolving pulp using sulfuric acid ( $63.5 \%$ by weight) hydrolysis at $45^{\circ} \mathrm{C}$ for $2 \mathrm{~h}$. CNC7 was produced from bleached Kraft wood pulp using sulfuric acid hydrolysis $(64 \%$ by weight) followed by dilution, separation and neutralization from residual acid and finally spray drying. CNC8 was produced from a pilot scale facility from rayon-grade dissolving pulp using a proprietary patented method called $\mathrm{AVAP}^{\circledR}[15]$ to liberate $\mathrm{CNCs}$ from a variety of biomass sources. CNC9 is produced from pulp sludge of the paper industry with acid hydrolysis, and detailed proprietary processing was not provided by the manufacturer. In general, more detailed information on CNC production and processing can be found in the literature [16]. 
Table 2. Characteristics of cellulose nanocrystals (CNCs) used.

\begin{tabular}{|c|c|c|c|c|c|c|c|}
\hline CNC type & Availability & Source & Form & Treatment & $\begin{array}{l}\text { Zeta potential } \\
(\mathrm{mV}) \text { at } \mathrm{pH} 13\end{array}$ & $\begin{array}{c}\text { Average } \\
\text { particle } \\
\text { length }(\mathrm{nm})\end{array}$ & $\begin{array}{c}\text { Aspect } \\
\text { ratio }\end{array}$ \\
\hline CNC1 & Lab-made & Wood pulp & $\begin{array}{l}\text { Aqueous } \\
\text { suspension }\end{array}$ & $\begin{array}{l}\text { Sulfuric acid } \\
\text { hydrolysis }\end{array}$ & -44 & 93 & 13 \\
\hline $\mathrm{CNC} 2$ & Lab-made & Cotton fiber & $\begin{array}{l}\text { Aqueous } \\
\text { suspension }\end{array}$ & $\begin{array}{l}\text { Sulfuric acid } \\
\text { hydrolysis }\end{array}$ & -47 & 127 & 14 \\
\hline $\mathrm{CNC3}$ & Lab-made & Algae (Cladophora) & $\begin{array}{l}\text { Aqueous } \\
\text { suspension }\end{array}$ & $\begin{array}{l}\text { Sulfuric acid } \\
\text { hydrolysis }\end{array}$ & -42 & 966 & 46 \\
\hline CNC4 & Commercial & $\begin{array}{l}\text { Acetate-grade } \\
\text { dissolving pulp }\end{array}$ & $\begin{array}{c}\text { Aqueous } \\
\text { suspension }\end{array}$ & $\begin{array}{l}\text { Transition metal } \\
\text { catalyzed } \\
\text { oxidation }\end{array}$ & -39 & 125 & 11 \\
\hline CNC5 & Commercial & $\begin{array}{l}\text { Acetate-grade } \\
\text { dissolving pulp }\end{array}$ & $\begin{array}{l}\text { Aqueous } \\
\text { suspension }\end{array}$ & Natural oxidation & -34 & 83 & 12 \\
\hline CNC6 & Commercial & Wood pulp & Dry powder & $\begin{array}{l}\text { Sulfuric acid } \\
\text { hydrolysis }\end{array}$ & -49 & 90 & 12 \\
\hline CNC7 & Commercial & Wood pulp & Dry powder & $\begin{array}{l}\text { Sulfuric acid } \\
\text { hydrolysis }\end{array}$ & -55 & 85 & 11 \\
\hline $\mathrm{CNC} 8$ & Commercial & $\begin{array}{l}\text { Rayon-grade } \\
\text { dissolving pulp }\end{array}$ & $\begin{array}{l}\text { Aqueous } \\
\text { suspension }\end{array}$ & $\begin{array}{l}\text { Sulfuric acid } \\
\text { hydrolysis }\end{array}$ & -21 & 184 & 15 \\
\hline CNC9 & Commercial & $\begin{array}{l}\text { Pulp sludge from } \\
\text { paper industry }\end{array}$ & $\begin{array}{l}\text { Aqueous } \\
\text { suspension }\end{array}$ & $\begin{array}{l}\text { Controlled acid } \\
\text { hydrolysis }\end{array}$ & -53 & 156 & 17 \\
\hline
\end{tabular}

As shown in Table 2, CNC particle dimensions were measured. Particle dimensions were determined by imaging samples using a Philips CM-100 TEM (FEI, Hillsboro, OR, USA) operated at $100 \mathrm{kV}$. At least 250 measurements were taken for each CNC. In terms of particle size, eight out of nine CNCs were similar and in the range of $80-200 \mathrm{~nm}$ in length with aspect ratio values of 10-20. CNC3 was made from an algae species with a much larger particle size (approximately $1000 \mathrm{~nm}$ ) and an aspect ratio of 46 . The zeta potential is a measurement of the potential difference between the dispersion medium and the stationary layer of fluid attached to the dispersed particles. The zeta potential of $\mathrm{CNC}$ aqueous suspensions $(0.5 \%$ by weight of dry $\mathrm{CNC})$ was measured in a controlled $\mathrm{pH}$ of 13 with the Zetasizer Nano ZS equipment (Malvern Instruments, Westborough, MA, USA). Most CNCs have a high zeta potential (between -40 and $-60 \mathrm{mV}$ ) to avoid flocculation and to achieve good dispersion with good stability.

\subsection{CNC-Cement Composite Preparation}

CNCs were added to the cement at dosages of $0.2 \%, 0.5 \%, 1.0 \%, 1.5 \%$ and $2.0 \%$ (volume fraction of the cement). These dosages were selected based on previous research where Cao et al. [8] showed that $1.35 \%$ (by volume) was a critical CNC dosage needed to cause significant agglomeration based on the percolation model, as well as rheology measurements. The required CNC aqueous suspension for the composites was measured by weight considering (1) the density of the CNC (1.6 g/ $\mathrm{cm}^{3}$ [7]), (2) the $\mathrm{CNC}$ dosage and (3) the $\mathrm{CNC}$ concentration in the aqueous suspension. A water-to-cement ratio $(w / c)$ of 0.40 was selected for Type I/II cement and 0.36 for Type V cement. These $w / c$ were selected based on the mixed consistency of the pastes. It was difficult to achieve a workable mixture without a water reducer in the vacuum mixer for Type I/II cement paste with a $w / c$ below 0.40 . On the other hand, a Type $\mathrm{V}$ cement paste with $w / c$ above 0.36 will cause segregation.

To prepare the CNC-cement composites, a Twister Evolution (Renfert USA, St Charles, IL, USA) vacuum mixer with $500 \mathrm{~mL}$ bowl was used to ensure consistent mixing action with reduced entrapped air (to reduce the flaw size in particles) due to the low vacuum environment. The CNC aqueous suspension was premixed with additional mixing water (deionized) in a beaker with a magnetic stirrer for 45-60 min. During mixing, water containing CNCs was added first to the mixing bowl, then cement was added. Then, the mixer was set to mix at $400 \mathrm{rpm}$ under $70 \%$ of vacuum for two $90-\mathrm{s}$ sessions. In between, a spatula was used to scrape the mixing blade. After the mixing was completed, the fresh paste was transferred to the desired containers immediately. 


\subsection{Isothermal Calorimetry and Thermogravimetric Analysis}

IC is a useful tool to investigate cement hydration. It can be used to assess hydration kinetics (heat flow) and the degree of hydration (total cumulative heat release). Approximately $7 \mathrm{~g}$ of fresh paste were placed and sealed in a glass ampoule, then tested in a TAM Air system (TA Instruments, New Castel, DE, USA). The testing chamber was set to be $23 \pm 0.02{ }^{\circ} \mathrm{C}$ and had a stable baseline. The heat release of the hydration reactions was monitored for 7 days $(168 \mathrm{~h})$.

At the end of the IC test, the hardened CNC-cement composites in the ampoule were used for TGA testing. To avoid potential carbonation, extra samples were stored in the ampoule in a sealed condition and tested using TGA at 28 days. These samples were crushed and ground with a mortar and pestle and passed through a $0.5-\mathrm{mm}$ (No. 35) sieve. Approximately $30 \mathrm{mg}$ of sieved powder were transferred to the platinum pan for TGA. The sample was heated to $1000{ }^{\circ} \mathrm{C}$ in a nitrogen-purged furnace at a rate of $20^{\circ} \mathrm{C} / \mathrm{min}$. Sample mass at $105^{\circ} \mathrm{C}$ without evaporable water was taken as the baseline. The degree of hydration $(\mathrm{DOH})$ can be calculated by determining the total chemically-bound water (CBW) in paste samples using TGA [17]. Cao et al. showed that the CBW increased with an increase of the CNC dosage [9]. TGA is also particularly useful to quantify calcium hydroxide $(\mathrm{CH})$ content. $\mathrm{CH}$ content can also be used to estimate the degree of hydration for plain Portland cement systems (and within a single cement composition). To accurately determine $\mathrm{CH}$ content, a careful interpretation of the TGA curves is required. In this study, the determination of the $\mathrm{CH}$ content is done following a "modified" procedure proposed by Kim et al. [18]. The "modified" procedure considers the mass loss due to other phases in the $\mathrm{CH}$ temperature range $\left(380-480^{\circ} \mathrm{C}\right)$ and removes these from the calculation of the $\mathrm{CH}$ mass loss.

\subsection{Ball-On-Three-Ball Test}

Fresh paste was cast into plastic cylinder molds $(\varphi 50 \mathrm{~mm} \times 100 \mathrm{~mm}$ ) for the B3B test. These samples were sealed in plastic bags at $23 \pm 1{ }^{\circ} \mathrm{C}$ until the desired testing age (3, 7 and 28 days). Prior to testing, hardened samples were wet cut using a diamond saw into $2.5 \pm 0.2 \mathrm{~mm}$-thick discs and tested using a universal testing machine. Note that for each cylinder, the surface layer (approximately $10 \mathrm{~mm}$ in thickness) was cut and discarded. The testing setup is shown in Figure 1. The test setup features a center load on a disc sample, with three supporting balls at an angle of $120^{\circ}$ to each other underneath the sample. To calculate B3B flexural strength, peak load at failure and sample thickness are needed. Details of this calculation can be found in the literature $[19,20]$. Six discs were prepared and tested for each mixture at each different age to provide data with statistical significance. The coefficient of variation $(\mathrm{COV})$ within a set of tests was in the range of $2-10 \%$.
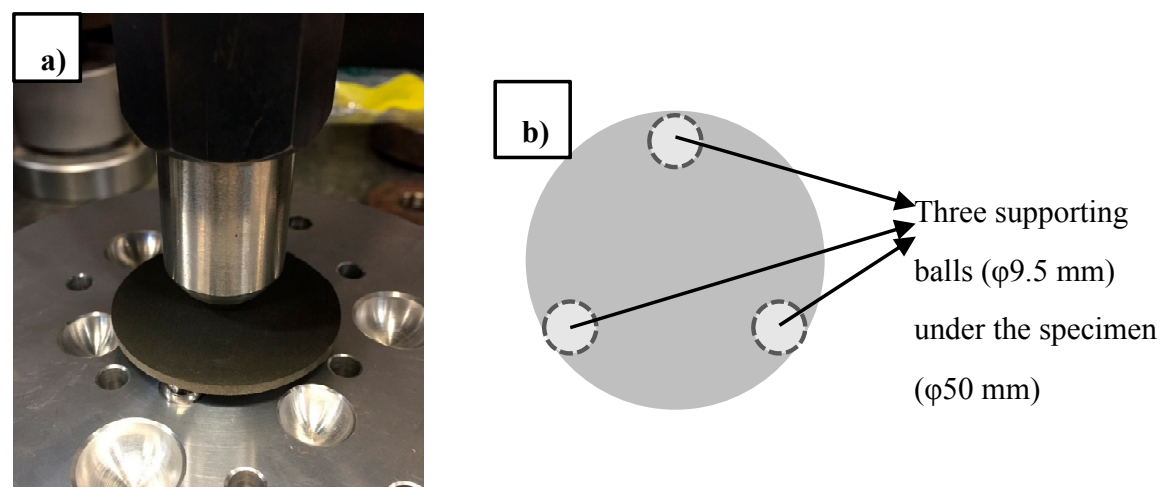

Figure 1. (a) Photo of the ball-on-three-ball (B3B) fixture with a specimen; (b) top view (dimensions) of the testing setup.

The B3B test has been used to test brittle materials [20,21]. The B3B test has also been successfully applied to cementitious materials $[8,9,19,22-24]$. It has several advantages over a traditional bending 
test. First of all, the test is reported to be less sensitive to small geometrical imperfections [25], and free from edge defects of the sample [25]. In addition, friction has only a minor effect on the test results [25]. The B3B test requires small samples, which can be prepared in large quantities by sectioning thin disc samples from hardened cement paste cylinders.

\section{Results and Discussion}

\subsection{Isothermal Calorimetry}

Heat flow curves are shown in Figures 2-5. Table 3 shows that the total (cumulative) heat release normalized by the mass of cement at seven days was higher with all CNC mixtures as compared to the control mixture. This implies that all mixtures with CNCs showed an increased degree of hydration.

Table 3. Effect of CNCs on cement hydration.

\begin{tabular}{ccccc}
\hline \multirow{2}{*}{ Mix } & \multicolumn{2}{c}{$\begin{array}{c}\text { Difference in time to reach } \\
\text { peak heat flow: (h) }\end{array}$} & $\begin{array}{c}\text { Heat (J/g) at 7 days } \\
\text { (difference comparing to control) }\end{array}$ \\
\cline { 2 - 5 } & Type I/II & Type V & Type I/II & Type V \\
\hline Control & $-*$ & $-*$ & $308(-)$ & $237(-)$ \\
CNC1 0.2\% & 1.0 & 3.3 & $319(3.6 \%)$ & $255(7.6 \%)$ \\
CNC1 0.5\% & 1.5 & 4.0 & $319(3.6 \%)$ & $258(8.9 \%)$ \\
CNC1 1.0\% & 2.1 & 4.8 & $320(4.0 \%)$ & $269(13.5 \%)$ \\
CNC1 1.5\% & 2.3 & 4.7 & $322(4.7 \%)$ & $280(18.1 \%)$ \\
CNC1 2.0\% & 2.3 & 7.7 & $319(3.6 \%)$ & $292(23.2 \%)$ \\
CNC2 0.2\% & 0.9 & 2.3 & $320(3.9 \%)$ & $260(9.7 \%)$ \\
CNC3 0.2\% & -0.8 & 1.8 & $314(1.9 \%)$ & $271(14.3 \%)$ \\
CNC4 0.2\% & 1.9 & 12.6 & $321(4.2 \%)$ & $259(9.3 \%)$ \\
CNC4 0.5\% & 4.6 & 98.8 & $328(6.5 \%)$ & $251(5.9 \%)$ \\
CNC4 1.0\% & 11.5 & $>168 * *$ & $334(8.6 \%)$ & $4.1 * *(-98.1 \%)$ \\
CNC5 0.2\% & 1.7 & 5.6 & $322(4.5 \%)$ & $263(11.0 \%)$ \\
CNC6 0.2\% & 1.7 & 3.4 & $319(3.6 \%)$ & $260(9.7 \%)$ \\
CNC7 0.2\% & 1.5 & 4.4 & $321(4.2 \%)$ & $262(10.5 \%)$ \\
CNC8 0.2\% & 0.7 & 2.4 & $322(4.5 \%)$ & $259(9.3 \%)$ \\
CNC9 0.2\% & 1.1 & 3.7 & $322(4.5 \%)$ & $267(12.7 \%)$ \\
\hline
\end{tabular}

* Time to reach peak heat flow: $7.1 \mathrm{~h}$ (Type I/II) and $11.4 \mathrm{~h}$ (Type V). ** Specimen did not set at 7 days.

Compared to the control paste, a retardation (a delay in the time to reach peak heat flow, listed in Table 3) can be consistently found in both Type I/II (Figure 2) and Type V (Figure 3) systems with different CNCs. One exception is CNC3 $0.2 \%$ with Type I/II cement, the results of which showed a slight acceleration (approximately $0.8 \mathrm{~h}$ ). This retardation effect was much more pronounced in the Type V systems (between 2 and $8 \mathrm{~h}$ ) than in the Type I/II system (between 40 min and $2 \mathrm{~h}$ ). It is believed that the cause of this phenomenon is the aluminate phase content difference between these two cement systems. A more detailed discussion is given in Section 3.4. In Type V systems (Figure 3), it is consistent among different CNCs that the major silicate hydration peak is increased. This effect in Type I/II systems is not as apparent for the major silicate hydration peak (approximately 7-8 $\mathrm{h}$ in Figure 2). However, the secondary aluminate hydration peak height (heat release rate) at $12 \mathrm{~h}$ was significantly increased with the presence of CNCs. More discussion on this topic is presented in Section 3.4. 


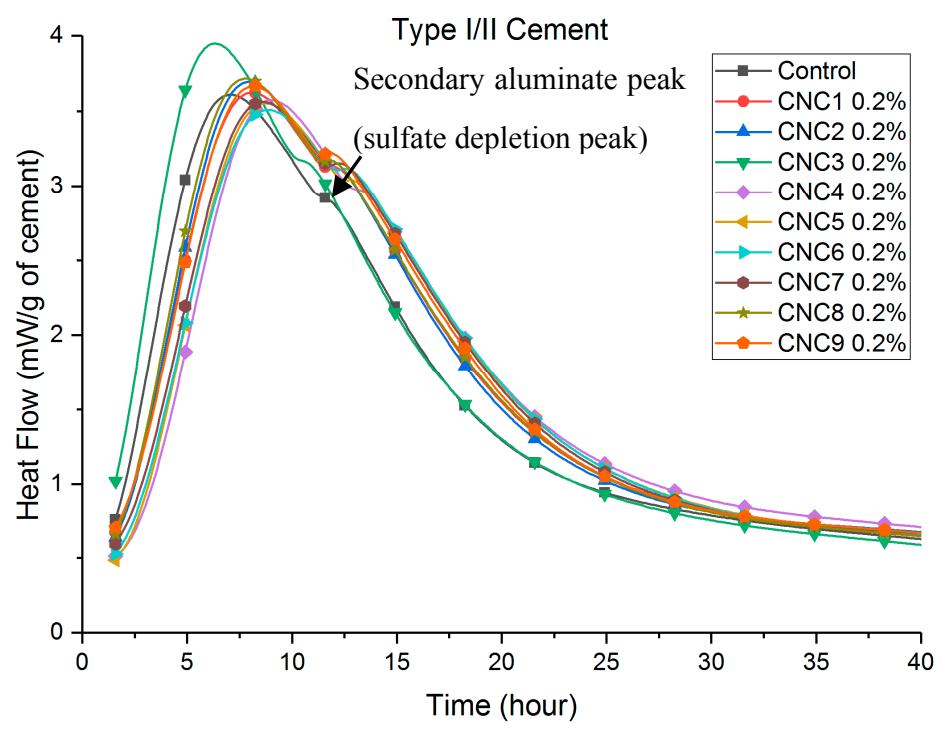

Figure 2. Heat flow of Type I/II cement, different CNCs.

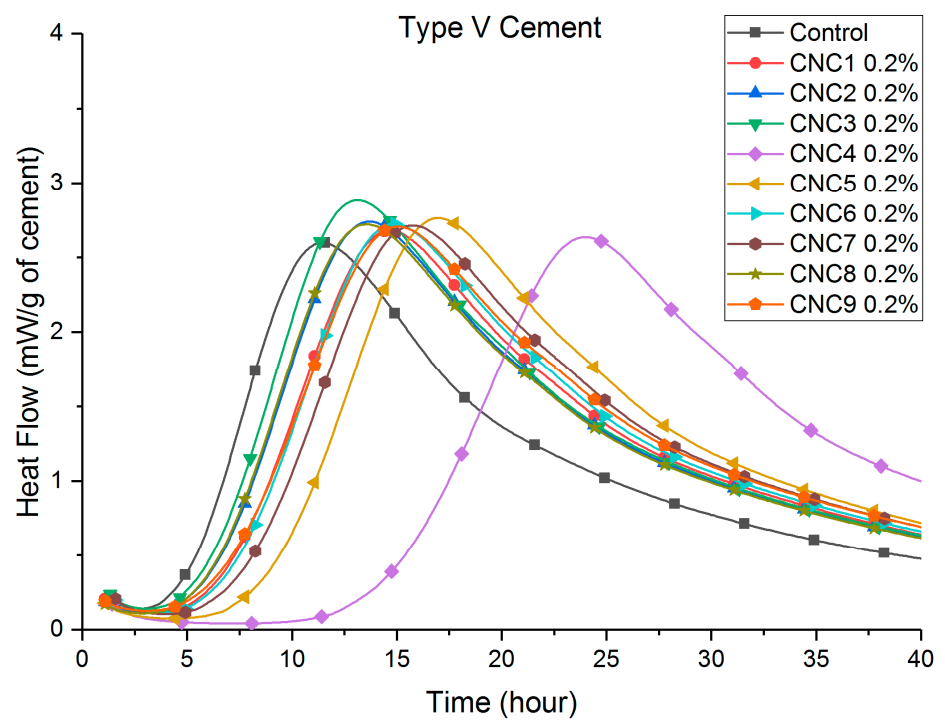

Figure 3. Heat flow of Type V cement, different CNCs.

Figures 4 and 5 show that the retardation increased consistently with an increase in the dosage of $\mathrm{CNC1}$. The cause of the retardation is believed to be a slower dissolution of $\mathrm{C}_{3} \mathrm{~S}$ caused by $\mathrm{CNCs}$ adhering to the surface reducing accessible water in the early age. It is also possible that the local chemistry and $\mathrm{pH}$ are changed at the surface of hydrating grains. Further research is underway to evaluate the impact of $\mathrm{pH}$. Similar results with superplasticizers have been shown in other research [26-30]. Similar effects on the height of the hydration peaks were observed with increasing dosage of CNCs. As shown in Figure 5, higher CNC dosages in Type V systems showed more rapid hydration for a longer time when considering the major silicate hydration peak. The height of the major silicate hydration peak in Type I/II systems (Figure 4) was not increased until the $2.0 \%$ $\mathrm{CNC}$ dosage. However, the height of the secondary aluminate hydration peaks (also referred to as the sulfate depletion peak) was significantly increased. The aluminate content in the cement was believed to cause this difference between Type I/II and Type V cement systems. More discussion is given in Section 3.4. 


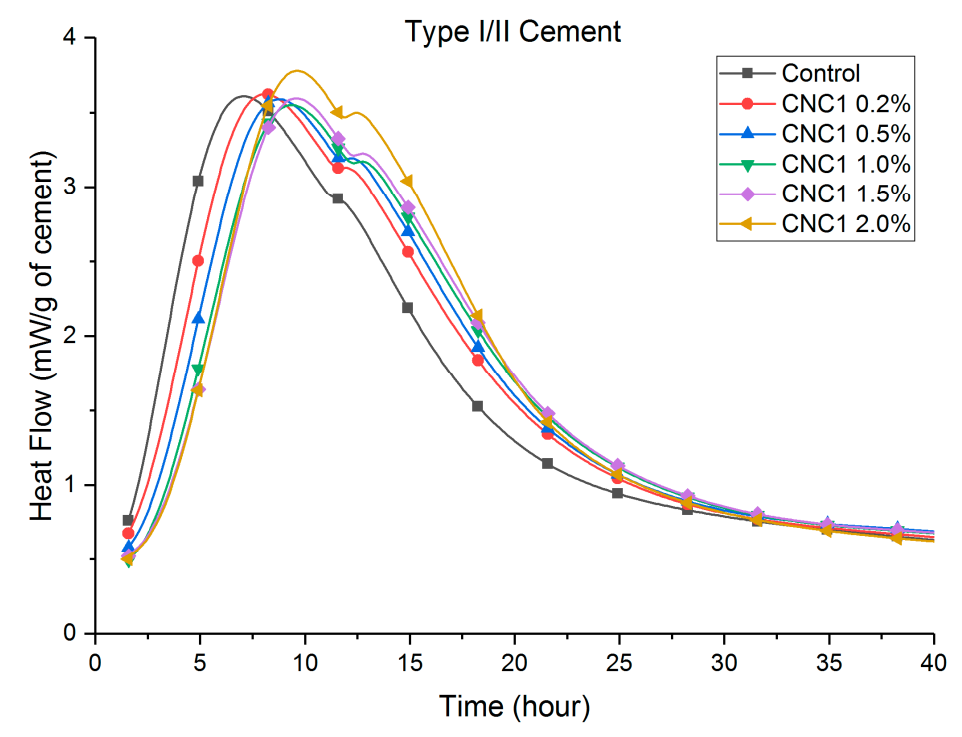

Figure 4. Heat flow of Type I/II cement, CNC1 at different dosages.

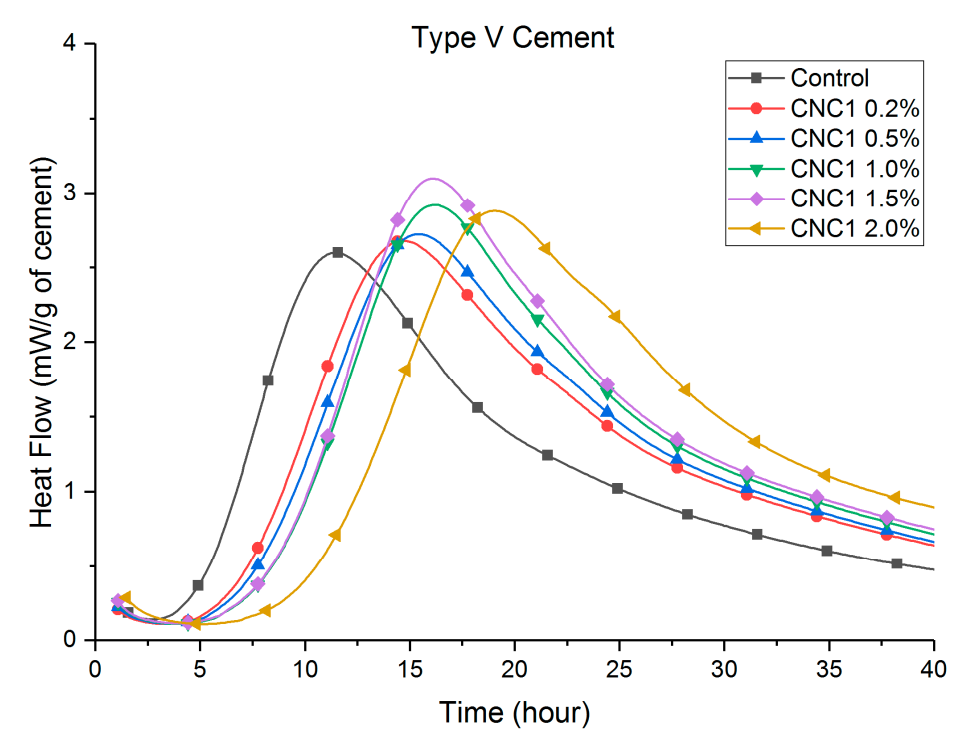

Figure 5. Heat flow of Type V cement, CNC1 at different dosages.

CNC4 at higher dosage showed significantly longer delay in both cement systems: $4.6 \mathrm{~h}$ for $0.5 \%$ and $11.5 \mathrm{~h}$ for $1.0 \%$ in Type I/II mixtures; and $12.6 \mathrm{~h}$ for $0.2 \%$ and $98.8 \mathrm{~h}$ for $0.5 \%$ in Type $\mathrm{V}$ mixtures, which may raise concerns when this particular CNC is used at these dosages. It should be noted that for CNC4 1.0\% in Type V cement, the paste did not set at room temperature until approximately 10 days. The significantly longer retardation caused by CNC4 is likely caused by the treatment method and resulting impurities (possibly sugars). It should be noted that $\mathrm{CNC} 4$ and $\mathrm{CNC} 5$ were produced from acetate pulp with an oxidative process instead of sulfuric acid hydrolysis. Additional research is ongoing to investigate this issue.

\subsection{Thermogravimetric Analysis}

TGA results in Table 4 show that the $\mathrm{CH}$ content increased with the presence of CNCs at seven days. Most $\mathrm{CNCs}$ mixtures also showed an increase in $\mathrm{CH}$ contents at 28 days, indicating an increase in the degree of hydration, although the increase was less significant than total heat release. These results support the previously-mentioned role of the CNC in increasing steric stabilization and providing 
SCD. This effect would diminish with time since the later the age, a thicker hydrate shell (growing both inward and outward) therefore results in longer times for water transport [9]. This effect can also be seen in Figures 2-5, where the increased hydration heat release rate reverts back to the rate of the control sample after approximately $40 \mathrm{~h}$ for Type I/II systems and after approximately $80 \mathrm{~h}$ (not shown) for the Type V systems.

Table 4. Summary of TGA results. $\mathrm{CH}$, calcium hydroxide.

\begin{tabular}{ccccc}
\hline \multirow{2}{*}{ Mix ID } & \multicolumn{2}{c}{ Type I/II } & \multicolumn{2}{c}{ Type V } \\
\cline { 2 - 5 } & \multicolumn{2}{c}{ CH content, $\%$} & \multicolumn{2}{c}{ CH content, $\%$} \\
\cline { 2 - 5 } & 7 days & $\mathbf{2 8}$ days & 7 days & 28 days \\
\hline Control & 11.0 & 11.5 & 11.7 & 12.5 \\
CNC1 0.2\% & 11.1 & 11.8 & 11.9 & 11.8 \\
CNC1 0.5\% & 11.4 & 11.6 & 12.2 & 11.9 \\
CNC1 1.0\% & 11.5 & 12.3 & 12.6 & 12.6 \\
CNC1 1.5\% & 11.4 & 11.4 & 13.0 & 13.3 \\
CNC1 2.0\% & 11.7 & 11.8 & 13.4 & 13.8 \\
CNC2 0.2\% & 11.4 & 11.6 & 13.1 & 12.5 \\
CNC3 0.2\% & 11.6 & 12.4 & 13.2 & 13.5 \\
CNC4 0.2\% & 11.7 & 12.6 & 12.6 & 12.7 \\
CNC4 1.0\% & 11.7 & 13.0 & $-*$ & 13.2 \\
CNC5 0.2\% & 11.4 & 11.9 & 13.4 & 12.9 \\
CNC6 0.2\% & 11.3 & 11.8 & 12.2 & 12.5 \\
CNC7 0.2\% & 11.1 & 12.3 & 12.5 & 13.2 \\
CNC8 0.2\% & 11.6 & 11.9 & 12.9 & 13.0 \\
CNC9 0.2\% & 11.7 & 11.7 & 12.9 & 12.8 \\
\hline
\end{tabular}

\subsection{B3B Flexural Strength}

At $0.2 \%$ CNC dosage, the B3B flexural strength results at 3, 7 and 28 days are shown in Figure 6 . Most CNC mixtures showed increased B3B flexural strength in the Type V systems (Figure 6a). For the sake of brevity, only the error bars of the mixtures with statistically-significant increases are shown. They are $\mathrm{CNC} 1, \mathrm{CNC} 2, \mathrm{CNC} 3$ and $\mathrm{CNC} 4$. However, among these four $\mathrm{CNCs}$ at a $0.2 \%$ dosage, only CNC4 showed a significant increase in the B3B flexural strength in the Type I/II system. In addition, CNC4 worked particular well with the Type $\mathrm{V}$ system at a $0.2 \%$ dosage ( $45 \%$ increase at 28 days). This seems to be related to the processing treatment used in the manufacture of $\mathrm{CNC} 4$, which is different from the rest of the CNCs. More discussion on the possible reasons for this is given in Section 3.5.
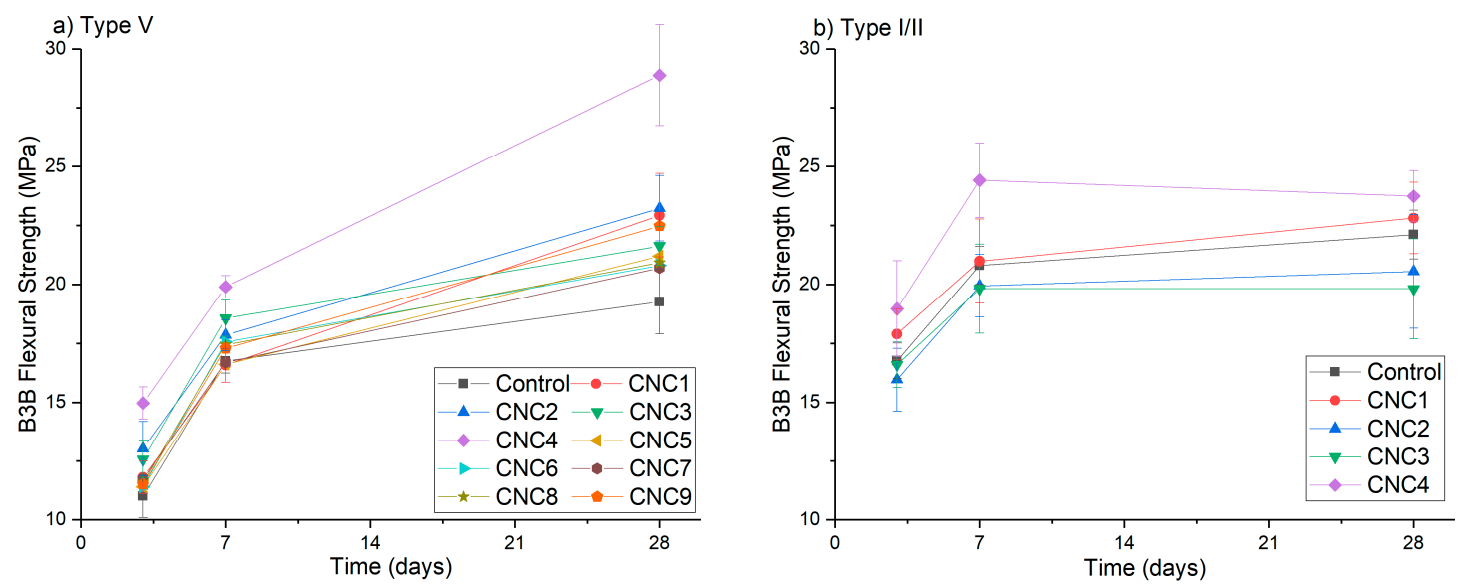

Figure 6. B3B flexural strength of cement with $0.2 \%$ CNCs: (a) Type V system; (b) Type I/II system. 
Figure 7 shows the effect of CNC dosage on B3B flexural strength for different cement systems. As shown in Figure 7a (Type V systems), at earlier ages (three days and seven days), the strength increased with $\mathrm{CNC} 1$ dosage until between $1.0 \%$ and $1.5 \%$. At 28 days, the optimum dosage seems to be approximately $0.5 \%$ (19\% strength increase); both rheology measurements and percolation theory suggest that an optimum CNC dosage exists to form a well-dispersed network [9]. At higher dosages, rheology measurements showed higher yield stress indicating greater $\mathrm{CNC}$ agglomeration, which is believed to act as defects leading to potential stress concentrations [9]. It has been shown that by using ultrasonication to disperse $\mathrm{CNC}$ in the mixing water, this optimum dosage (for the highest strength) can be increased to $1.35 \%$, which agrees well with the theoretical optimum value of $1.38 \%$ according to the percolation model [8].

Figure $7 \mathrm{~b}$ shows that B3B flexural strength increased with CNC dosages in Type I/II systems. At three days, considering the variability of the test, only the strength increase with CNC1 $2.0 \%(11 \%)$ is statistically significant. At later ages (even days and 28 days), the strength increase of CNC1 1.5\% and CNC $2.0 \%$ can also be considered significant. The difference in performance between Type I/II and Type $\mathrm{V}$ systems is believed to be caused by the difference in aluminate content. More discussion is provided in Section 3.4.

Figure 7c shows the strength results of CNC4 in the Type I/II cement system. At 28 days, the strength increased linearly with the dosage. However, as shown in Table 3, a higher dosage of CNC4 caused significant retardation in both the Type I/II and Type V cement systems. This is likely to be the reason why the strength of CNC4 $1.0 \%$ was reduced at seven day. This effect was even more pronounced at three days, where the strength was reduced with $\mathrm{CNC}$ dosage beyond $0.2 \%$. This suggests that although it is highly effective at increasing B3B strength, the dosage of CNC4 should be carefully selected, and higher dosages might need to be avoided depending on the application.
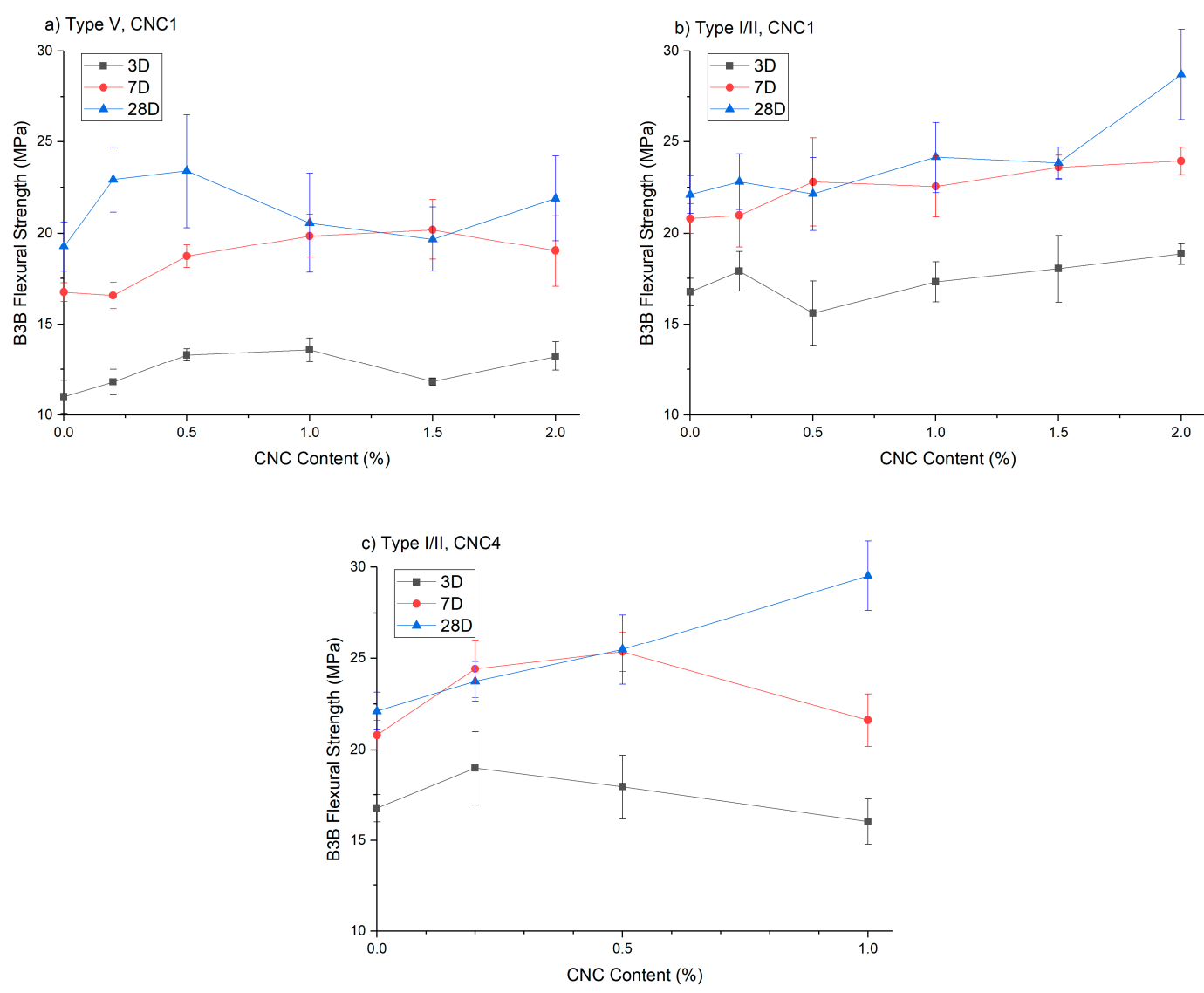

Figure 7. B3B flexural strength of cement with different CNC content: (a) Type V cement with CNC1; (b) Type I/II cement with CNC1; (c) Type I/II cement with CNC4. 
In terms of efficiency, an interesting question to ask is which cement systems work better with CNCs. A comparison between strength increase (\%) and heat release increase (\%) at seven days is shown in Figure 8. Error bars (standard deviation as a percentage of the control paste strength) of B3B flexural strengths are also shown in the figure. The standard deviation for heat release measurements is approximately $0.3 \%$ (measured for the cement paste without $\mathrm{CNCs}$ ); therefore, the error bars for heat release increase are not shown in Figure 8. Any point that lies above the 1:1 line indicates that for that particular $\mathrm{CNC}$ type and dosage, the increase in flexural strength is higher than the increase in heat release, which points to an additional microstructural enhancement effect in addition to the increase in the degree of hydration indicated by heat release. The results from Figure 8 indicate that $\mathrm{CNC} 1$ and $\mathrm{CNC} 4$ are two effective and efficient CNCs to work with both cement systems. As pointed out earlier, special caution needs to be exercised in selecting $\mathrm{CNC}$ dosages to avoid unwanted retardation. The reason for this enhanced flexural strength increase can be attributed to an enhanced $\mathrm{C}-\mathrm{S}-\mathrm{H}$ that forms. This is confirmed from the literature: Cao et al. [10] showed that the C-S-H formed in the presence of CNCs had a higher modulus of elasticity, and Flores et al. [11] showed a higher fraction of high density C-S-H. An interesting observation from Figure 8 is that although CNCs resulted in having a much lower heat release increase in the Type I/II systems, they can be as efficient at increasing the B3B flexural strength in Type I/II systems as in Type V systems.

Figure 9 shows a comparison between B3B flexural strength and heat release at seven days for $\mathrm{CNC} 1$ samples. At lower dosages $(0.2 \%)$, the $\mathrm{CNC} 1$ increased the heat release for both cement systems. However, the $\mathrm{B} 3 \mathrm{~B}$ flexural strengths were not affected by $\mathrm{CNC} 1$, indicating no significant change to the microstructures at this dosage. As the $\mathrm{CNC} 1$ dosage increases, both $\mathrm{B} 3 \mathrm{~B}$ flexural strength and heat release increased significantly. Then, at higher dosage (2.0\%), agglomerations of CNCs acted as defects, offsetting the benefit of the enhanced microstructure. In other words, there seems to exist an optimum dosage for the benefit of strength in CNC-cement composites.

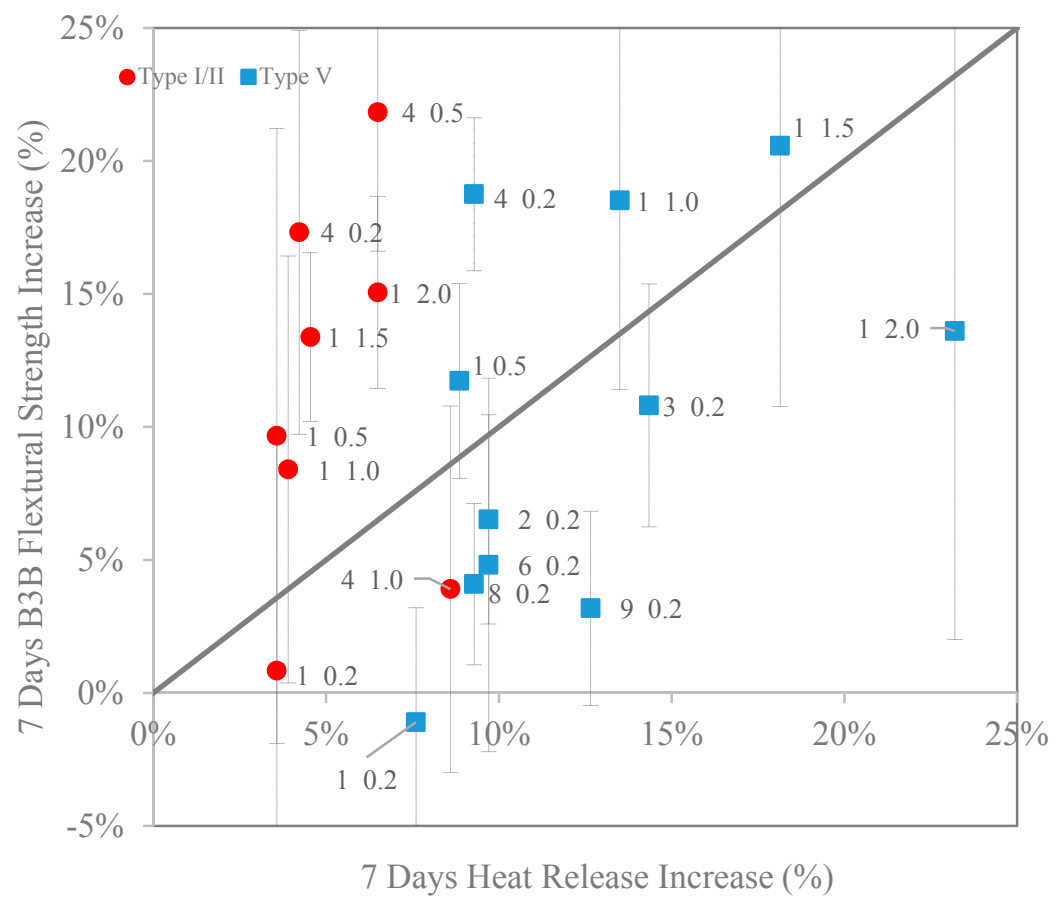

Figure 8. Comparison between B3B flexural strength and heat release increase (\%). The label next to data denotes CNC type (number) and dosage (percentage) (note: for B3B flexural strength, the COV of the Type I/II control is $3.9 \%$, and the COV of the Type V control is $3.0 \%$ ). 


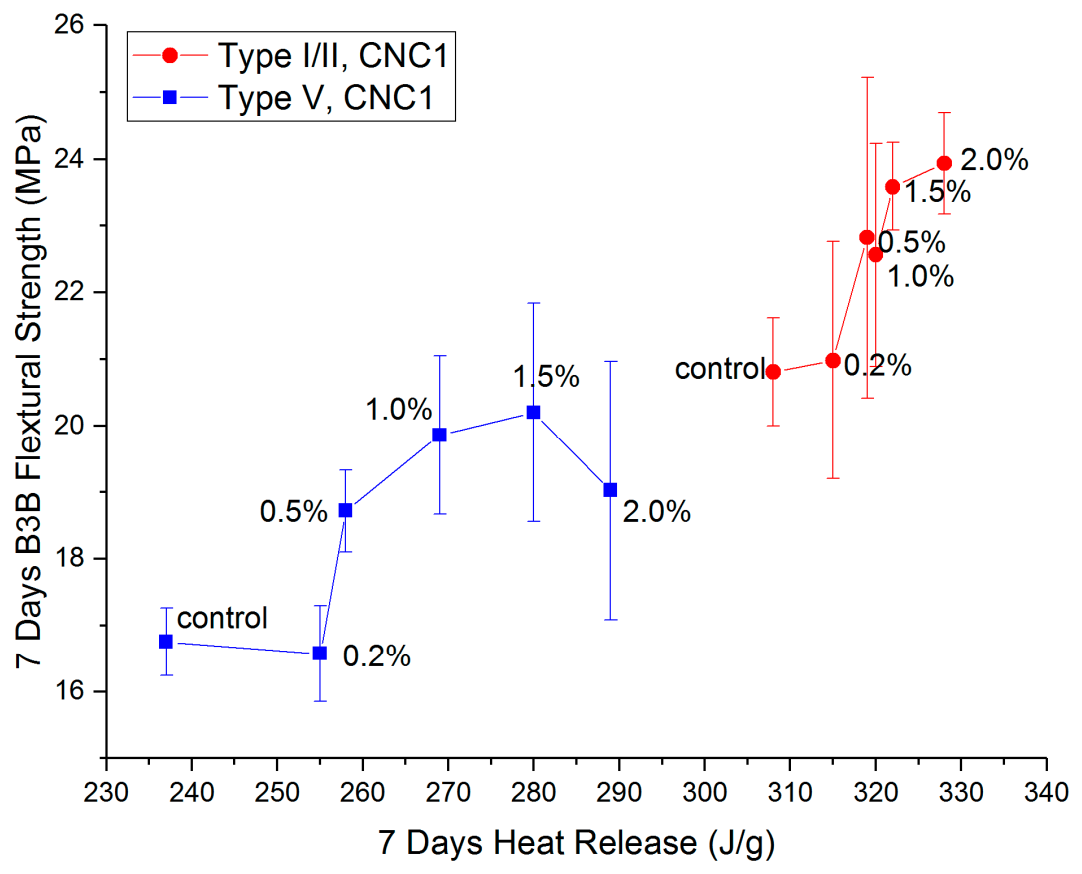

Figure 9. Comparison between B3B flexural strength and heat release for CNC1 with Type I/I and Type V cements.

\subsection{Effect of Aluminate Content}

At seven days, heat release increases with CNCs (compared to the control) with the Type V systems were twice as much as those observed in the Type I/II system. Considering the compositional difference between these cements (Table 1), the cause is likely to be the difference in the tricalcium aluminate $\left(\mathrm{C}_{3} \mathrm{~A}\right)$ contents. It is known that hydrated $\mathrm{C}_{3} \mathrm{~A}$ phases (ettringite and monosulfate) tend to absorb greater amounts of the polycarboxylate type of superplasticizer than other hydrated phases [26-29,31]. It is likely that similar mechanisms hold true here and that the effectiveness of the CNCs strongly depends on the tricalcium aluminate amount in the system. This can explain the higher silicate hydration peaks in Figures 3 and 5 for Type V systems ("zero" $C_{3} A$ ). While in Type I/II systems, as shown in Figures 2 and 4, the increase in the silicate hydration peaks (if at all) is insignificant, secondary aluminate hydration peaks are significantly increased. These interactions can be better understood by considering a few $\mathrm{CNC}$ s as examples. A closer look at $\mathrm{CNC} 1 \mathrm{in}$ both cement systems reveals that (1) in Type $\mathrm{V}$ cement paste, the heat release consistently increased with an increase of the CNC dosage and (2) in Type I/II cement pastes, a CNC dosage lower than $1.5 \%$ resulted in a similar increase in the heat release. It is possible that at a high CNC dosage (2.0\% in Type I/II cement), the surfaces of aluminate phases are "saturated" with CNCs, and after this point, a greater amount of the silicate phase surface is now covered with $\mathrm{CNCs}$ and results in a higher degree of hydration at later ages. Furthermore, the difference in $\mathrm{C}_{3} \mathrm{~A}$ content is likely responsible for the different retardation effect observed in these two systems. Cao et al. [9] reported that CNC1 can cause retardation in the Type V cement system due to $\mathrm{CNC}$ particles adhering to the unhydrated cement particles during early-age hydration (a similar effect as with some water-reducing admixtures). In the Type I/II system tested in this research, due to the presence of the $\mathrm{C}_{3} \mathrm{~A}$ phases, less CNCs adhered to silicate phases, resulting in less retardation in this system.

A comparison between heat release increase (\%) and $\mathrm{CH}$ content increase (\%) is shown in Figure 10. Type $\mathrm{V}$ cement with $\mathrm{CNC}$ shows both a higher $\mathrm{CH}$ content increase, as well as a higher heat release increase than the Type I/II system. In the Type V system, different dosages of CNC1 are highlighted in Figure 10 with a trend line, and a strong correlation $\left(R^{2}=0.98\right)$ between the heat release and the $\mathrm{CH}$ content was found. However, this correlation does not seem to exist in the Type I/II system. The heat 
release increase and $\mathrm{CH}$ content increase are both less than approximately $5 \%$. This is likely because at a lower $\mathrm{CNC}$ dosage $(0.2 \%)$, the increase is due to the enhanced aluminate phase hydration rather than the silicate hydration. At higher dosages (CNC1 2.0\% and CNC4 1.0\%, as pointed out in Figure 10), the aluminate phase is likely "saturated", and the heat release increase is a combination of increased aluminate hydration and silicate hydration.

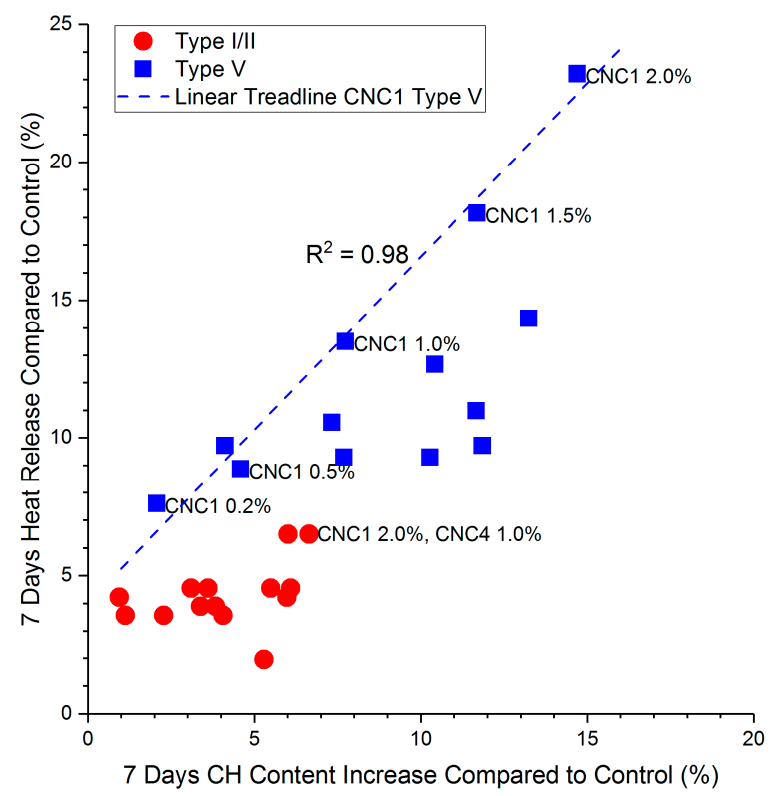

Figure 10. Comparison between the increase in total heat release (\%) and the $\mathrm{CH}$ content increase (\%) at 7 days.

\subsection{Comments on CNCs Source and Treatment}

Table 5 shows a summary of the effects of different $\mathrm{CNC}$ s on $\mathrm{CH}$ content, heat release and B3B flexural strength at seven days for both Type I/II and Type V systems. The comparison focuses on the average length and surface charge of different CNCs. CNCs are ranked from shorter to longer in terms of average particle length. No clear relationship exists between average CNC particle length and their effect on hydration and strength. This holds true for surface charge as well.

Table 5. Effect of different $\mathrm{CNC}$ on $\mathrm{CH}$ content, heat release and B3B flexural strength.

\begin{tabular}{ccccccccc}
\hline & & \multirow{3}{*}{$\begin{array}{c}\text { Zeta potential } \\
\text { Average length (nm) }\end{array}$} & Mixture ID & \multicolumn{4}{c}{ Increase comparing to control at 7 days } \\
\cline { 4 - 8 } & & & \multicolumn{3}{c}{ Type I/II } & \multicolumn{4}{c}{ Type V } \\
\cline { 4 - 8 } & & & $\mathbf{C H}$ & Heat & B3B & $\mathbf{C H}$ & Heat & B3B \\
\hline 83 & CNC5 & -34 & $3.1 \%$ & $4.5 \%$ & - & $11.7 \%$ & $11.0 \%$ & $-0.8 \%$ \\
85 & CNC7 & -55 & $0.9 \%$ & $4.2 \%$ & - & $7.3 \%$ & $10.5 \%$ & $-0.4 \%$ \\
90 & CNC6 & -49 & $2.3 \%$ & $3.6 \%$ & - & $4.1 \%$ & $9.7 \%$ & $4.9 \%$ \\
93 & CNC1 & -44 & $1.1 \%$ & $3.6 \%$ & $0.8 \%$ & $2.1 \%$ & $7.6 \%$ & $-1.1 \%$ \\
125 & CNC4 & -39 & $6.0 \%$ & $4.2 \%$ & $17.3 \%$ & $7.7 \%$ & $9.3 \%$ & $18.7 \%$ \\
127 & CNC2 & -47 & $3.4 \%$ & $3.9 \%$ & $-4.2 \%$ & $11.9 \%$ & $9.7 \%$ & $6.5 \%$ \\
156 & CNC9 & -53 & $6.1 \%$ & $4.5 \%$ & - & $10.4 \%$ & $12.7 \%$ & $3.2 \%$ \\
184 & CNC8 & -21 & $5.5 \%$ & $4.5 \%$ & - & $10.3 \%$ & $9.3 \%$ & $4.1 \%$ \\
966 & CNC3 & -42 & $5.3 \%$ & $1.9 \%$ & $-4.8 \%$ & $13.2 \%$ & $14.3 \%$ & $10.8 \%$ \\
\hline
\end{tabular}

In the Type I/II system, among the different CNCs, CNC4 was the most efficient in terms of increasing the heat release. This could be caused by its treatment method. The functional group in $\mathrm{CNC} 4$ and $\mathrm{CNC} 5$ is carboxylate (-COO-) (as acetate dissolving pulp is the source), compared to sulfate half-ester in other CNCs with sulfuric acid hydrolysis. This results in a surface charge of 
approximately $0.2 \mathrm{mmol}$ carboxylate/g in CNC4 [32] compared to $0.3 \mathrm{mmol}$ sulfate half-ester/g in CNC1 [16]. Furthermore, considering the "hard and soft acids and bases" (HSAB) theory, also known as the Pearson acid base concept [33], sulfate half-ester is a "harder" charge than carboxylate, therefore causing $\mathrm{CNC} 1$ to be more "preferentially" adsorbed onto aluminate phases. However, as $\mathrm{pH}$ in the pore solution increases quickly beyond 12 in the first few minutes [34], both sulfate half-ester and carboxylate are possibly deprotonated and a have similar charge. As discussed previously, CNC4 caused severe retardation in Type $\mathrm{V}$ cement; therefore, caution should be exercised before using this particular CNC with Type V cement.

\section{Conclusions}

This study examined nine CNCs made from different raw material sources and with different processing techniques. The CNCs were tested with two cement compositions (Type I/II and Type V) using isothermal calorimetry (IC), thermogravimetric analysis (TGA) and the ball-on-three ball (B3B) flexural strength test. Several important conclusions can be drawn:

- The degree of hydration increased for all CNC mixtures for both Type I/II ( 5\%) and Type V (10-20\%) cement systems, as determined via heat release and $\mathrm{CH}$ content measurements;

- $\quad$ All CNCs (except for CNC3 in Type V cement) showed a mild retardation effect at early ages. At higher dosages $(>0.5 \%), \mathrm{CNC} 4$ can cause significant retardation, which might raise concerns depending on the desired application for use of this particular CNC;

- All CNCs showed a greater increase in the heat release when Type V cement was used in comparison to Type I/II cement. The aluminate content in Type I/II cement is believed to decrease the SCD effect between silicate phases and CNC (especially at low dosage), resulting in less benefit seen in the Type $\mathrm{V}$ system;

- $\quad \mathrm{CNC} 1$ and $\mathrm{CNC} 4$ tested in the study showed promising results for increasing the B3B flexural strength (by approximately $20 \%$ in both the Type I/II and Type V systems). In addition, optimum CNC dosages seem to exist for Type I/II and Type V cement systems;

- $\quad \mathrm{CNC4}$ was particular effective at increasing hydration heat release and B3B flexural strength in both Type I/II and Type V cement systems. This was believed to relate to its treatment (transition metal catalyzed oxidation), which is different from the treatment of other CNCs (acid hydrolysis);

- The hydration and strength of CNC-cement composites do not appear to be sensitive to CNC particle length or surface charge (zeta potential).

- $\quad$ IC testing and B3B flexural strength testing can be used as practical screening tools for evaluating the performance of CNC-cement composites.

Acknowledgments: The authors would like to acknowledge the support from $\mathrm{P}^{3} \mathrm{Nano}$ and the U.S. Endowment for Forestry and Communities. The authors would also like to thank Alan Rudie from the U.S. Forest Products Laboratory and Michael Goergen from U.S. Endowment for Forestry \& Communities for their help and support in collecting the CNC materials. Special thanks to John Simonson from Wood Science and Engineering of Oregon State University for many insightful discussions.

Author Contributions: Jason Weiss, Jeffrey Youngblood and Tengfei Fu conceived of and designed the experiments. Tengfei Fu, Francisco Montes and Prannoy Suraneni performed the experiments and analyzed the data. Tengfei Fu wrote the paper.

Conflicts of Interest: The authors declare no conflict of interest.

\section{References}

1. Sanchez, F.; Sobolev, K. Nanotechnology in concrete-A review. Constr. Build. Mater. 2010, 24, $2060-2071$. [CrossRef]

2. Kawashima, S.; Hou, P.; Corr, D.J.; Shah, S.P. Modification of cement-based materials with nanoparticles. Cem. Concr. Compos. 2013, 36, 8-15. [CrossRef]

3. Moon, R.J.; Schueneman, G.T.; Simonsen, J. Overview of cellulose nanomaterials, Their capabilities and applications. JOM 2016, 68, 2383-2394. [CrossRef] 
4. Zubik, K.; Singhsa, P.; Wang, Y.; Manuspiya, H.; Narain, R. Thermo-responsive poly(N-isopropylacrylamide)cellulose nanocrystals hybrid hydrogels for wound dressing. Polymers 2017, 9, 119. [CrossRef]

5. Fu, T.; Moon, R.; Youngblood, J.; Zavattieri, P.; Weiss, J. 20-nanocellulose as additive for cement composites. In Cellulose-Reinforced Nanofiber Composites: Production, Properties and Applications; Woodhead Publishing: Cambridge, UK, 2017; pp. 445-482.

6. Siqueira, G.; Bras, J.; Dufresne, A. Cellulosic bionanocomposites: A review of preparation, properties and applications. Polymers 2010, 2, 728. [CrossRef]

7. Moon, R.J.; Martini, A.; Nairn, J.; Simonsen, J.; Youngblood, J. Cellulose nanomaterials review: Structure, properties and nanocomposites. Chem. Soc. Rev. 2011, 40, 3941-3994. [CrossRef] [PubMed]

8. Cao, Y.; Zavattieri, P.; Youngblood, J.; Moon, R.; Weiss, J. The relationship between cellulose nanocrystal dispersion and strength. Constr. Build. Mater. 2016, 119, 71-79. [CrossRef]

9. Cao, Y.; Zavaterri, P.; Youngblood, J.; Moon, R.; Weiss, J. The influence of cellulose nanocrystal additions on the performance of cement paste. Cem. Concr. Compos. 2015, 56, 73-83. [CrossRef]

10. Cao, Y.; Tian, N.; Bahr, D.; Zavattieri, P.D.; Youngblood, J.; Moon, R.J.; Weiss, J. The influence of cellulose nanocrystals on the microstructure of cement paste. Cem. Concr. Compos. 2016, 74, 164-173. [CrossRef]

11. Flores, J.; Kamali, M.; Ghahremaninezhad, A. An investigation into the properties and microstructure of cement mixtures modified with cellulose nanocrystal. Materials 2017, 10, 498. [CrossRef] [PubMed]

12. ACI Committee 544. State-of-the-Art Report on Fiber Reinforced Concrete; American Concrete Institute: Farmingon Hills, MI, USA, 1996; reapproved 2009.

13. Dubey, A. (Ed.) SP-224: Thin Reinforced Cement-Based Products and Construction Systems; American Concrete Institute: Farmington Hills, MI, USA, 2004.

14. Reiner, R.; Rudie, A. Process scaleup of cellulose nanocrystal production to $25 \mathrm{~kg}$ per batch at the forest products laboratory. In Production and Applications of Cellulose; Tappi Press: Peachtree Corners, GA, USA, 2013; pp. 21-24.

15. Nelson, K.; Retsina, T. Innovative nanocellulose process breaks the cost barrier. TAPPI J. 2014, 13, 19-23.

16. Reid, M.S.; Villalobos, M.; Cranston, E.D. Benchmarking cellulose nanocrystals: From the laboratory to industrial production. Langmuir 2017, 33, 1583-1598. [CrossRef] [PubMed]

17. Pane, I.; Hansen, W. Investigation of blended bement hydration by isothermal calorimetry and thermal analysis. Cem. Concr. Res. 2005, 35, 1155-1164. [CrossRef]

18. Kim, T.; Olek, J. Effects of sample preparation and interpretation of thermogravimetric curves on calcium hydroxide in hydrated pastes and mortars. Transp. Res. Rec. J. Transp. Res. Board 2012, 2290, 10-18. [CrossRef]

19. Cao, Y. Nano-Modification for High Performance Cement Composites with Cellulose Nanocrystals and Carbon Nanotubes. Ph.D. Dissertation, Purdue University, West Lafayette, IN, USA, 2014.

20. Börger, A.; Supancic, P.; Danzer, R. The ball on three balls yest for strength yesting of brittle discs: Stress distribution in the disc. J. Eur. Ceram. Soc. 2002, 22, 1425-1436. [CrossRef]

21. Montgomery, J.K.; Faber, K.T. Processing and surface flaw tolerance of alumina bilayers. J. Am. Ceram. Soc. 2005, 88, 287-292. [CrossRef]

22. Cao, Y.; Weiss, J.; Youngblood, J.; Moon, R.; Zavaterri, P. Performance-enhanced cementitious matrerials by cellulose nanocrystal additions. In Production and Applications of Cellulose Nanomaterials; TAPPI Press: Peachtree Corners, GA, USA, 2013; pp. 135-146.

23. Kim, J.; Yi, C.; Zi, G. Biaxial flexural strength of concrete by two different methods. Mag. Concr. Res. 2012, 64, 1057-1065. [CrossRef]

24. ASTM Standard C1550, Standard test Method for Flexural Toughness of Fiber Reinforced Concrete (Using Centrally Loaded Round Panel); ASTM International: West Conshohocken, PA, USA, 2012.

25. Börger, A.; Supancic, P.; Danzer, R. The ball on three balls test for strength testing of brittle discs: Part II: Analysis of possible errors in the strength determination. J. Eur. Ceram. Soc. 2004, 24, 2917-2928. [CrossRef]

26. Winnefeld, F.; Zingg, A.; Holzer, L.; Figi, R.; Pakusch, J.; Becker, S. Interaction of polycarboxylate-based superplasticizers and cements: Influence of polymer structure and $\mathrm{C}_{3} \mathrm{~A}$-content of cement. In 12th International Congress on Teh Chemistry of Cement; ICCC: Montréal, Quebec, QC, Canada, 2007.

27. Nawa, T. Effect of chemical structure on steric stabilization of polycarboxylate-based superplasticizer. J. Adv. Concr. Technol. 2006, 4, 225-232. [CrossRef]

28. Plank, J.; Hirsch, C. Impact of zeta potential of early cement hydration phases on superplasticizer adsorption. Cem. Concr. Res. 2007, 37, 537-542. [CrossRef] 
29. Gelardi, G.; Flatt, R.J. 11-Working mechanisms of water reducers and superplasticizers. In Science and Technology of Concrete Admixtures; Woodhead Publishing: Cambridge, UK, 2016; pp. 257-278.

30. Suraneni, P.; Flatt, R.J. Use of micro-reactors to obtain new insights into the factors influencing tricalcium silicate dissolution. Cem. Concr. Res. 2015, 78, 208-215. [CrossRef]

31. Cheung, J.; Jeknavorian, A.; Roberts, L.; Silva, D. Impact of admixtures on the hydration kinetics of portland cement. Cem. Concr. Res. 2011, 41, 1289-1309. [CrossRef]

32. Blue Goose Biorefineries Inc. Certificate of Analysis-Lot Number AUU06-002; Blue Goose Biorefineries Inc.: Saskatchewan, SK, Canada, 2016.

33. Pearson, R. Chemical Hardness_-Applications from Molecules to Solids; Wiley-VCH: Weinheim, Germany, 1997; p. 198.

34. Vollpracht, A.; Lothenbach, B.; Snellings, R.; Haufe, J. The pore solution of blended cements: A review. Mater. Struct. 2016, 49, 3341-3367. [CrossRef]

(C) 2017 by the authors. Licensee MDPI, Basel, Switzerland. This article is an open access article distributed under the terms and conditions of the Creative Commons Attribution (CC BY) license (http:/ / creativecommons.org/licenses/by/4.0/). 